\title{
ESCOLA É "VIDA NA COMUNIDADE": ANÁLISE SOBRE FECHAMENTO DE ESCOLAS DO CAMPO
}

\author{
SCHOOL IS "LIFE IN THE COMUNITY": ANALYSIS ON \\ RURAL SCHOOLS CLOSURE
}

\section{LA ESCUELA ES "VIDA EN LA COMUNIDAD": ANÁLISIS DEL CIERRE DE ESCUELAS EN EL CAMPO}

\author{
Margarete de Mattos ${ }^{1}$ \\ https://orcid.org/0000-0002-4518-438X \\ Elodir Lourenço de Souza ${ }^{2}$ \\ https://orcid.org/0000-0002-1252-0439 \\ Camila Munarini ${ }^{3}$ \\ https://orcid.org/0000-0002-1513-6694
}

Submissão: 30/10/2020 / Aceito: 22/03/2021 / Publicado: 30/09/2021

\begin{abstract}
Resumo
A temática fechamento de escola do campo tem sido fortemente discutida nos últimos anos em vários trabalhos científicos, sendo também fator de preocupação por parte das comunidades localizadas em área rural. Este artigo analisa a política de municipalização do ensino fundamental e de nucleação de escolas, indicando que tal política é o principal motivador do fechamento de milhares de escolas do campo no Brasil e de dezenas de escolas no Município de Passos Maia. Além disso, está elaboração apresenta dados sobre as escolas que foram fechadas no Município de Passos Maia e aponta os impactos negativos que a comunidade Conquista de Sepé obteve ao ser fechada sua escola local. Conclui-se, dessa forma, que fechar as Escolas do Campo provoca a destituição da organização social e da vivência comunitária. Nesta direção é que se localiza a afirmação de que Escola do Campo é "vida na comunidade", por compreende-se que o fechamento/extinção de escolas do campo leva ao fechamento/extinção das comunidades rurais. Como instrumentos metodológicos, para a elaboração do trabalho, foram utilizados estudo bibliográfico e entrevistas.
\end{abstract}

Palavras-Chave: Fechamento de escolas. Política de Nucleação. Educação do Campo.

\begin{abstract}
The theme rural school closure has been strongly discussed in the latest years in several cientific works, as well has been a fator of concern by the comunities located in rural areas. This article analyzes the policy of municipalization of elementary school and the nucleation of schools indicating the this kind of policy is the main rason for the closure of Thousands rural schools in Braszil and of dozens schools in Passos Maia municipality. Besides, this elaboration presentes data about schools that were closed in Passos Maia municipality and
\end{abstract}

\footnotetext{
${ }^{1}$ Especialista em Educação do Campo. Professora da Rede Municipal de Passos Maia. E-mail: margaretedematos25@gmail.com

${ }^{2}$ Mestre em Educação. Professor do Instituto Federal Catarinense. E-mail: elodir.souza@ifc.edu.br

${ }^{3}$ Mestre em Educação Científica e Tecnológica. Professora do Instituto Federal Catarinense. E-mail: camila.munarini@ifc.edu.br
} 
shows the negative impacts suffered by the community Conquista do Sepé when the local had its school closed. We conclude that the closure of rural schools causes the destituition of the social organization and communitary experience. In this Direction, is the afirmation that the rural school is "life in the community", because close or extinguish rural schools takes to the closure or extintion of rural communities. As methodological instruments, for this elaboration, we used bibliographic study and interviews.

Key-words: Schools closure, nucleation policy, field education.

\section{Resumen}

El tema cierre de Escuela del Campo ha sido fuertemente discutido en los últimos años en diversos trabajos científicos, y también es un factor de preocupación por parte de las comunidades ubicadas en áreas rurales. Este artículo analiza la política de municipalización de la educación básica y la nucleación de las escuelas, indicando que dicha política es la principal razón para el cierre de miles de escuelas rurales en Brasil y decenas de escuelas en el municipio de Passos Maia. Además, esta elaboración presenta datos sobre las escuelas que fueron cerradas en el Municipio de Passos Maia y señala los impactos negativos que obtuvo la comunidad Conquista de Sepé cuando se cerró su escuela local. Se concluye, de esa manera, que el cierre de las Escuelas del Campo provoca la destitución de la organización social y experiencia comunitaria. Es en esta dirección que se encuentra la afirmación de que Escuela del Campo es "vida en la comunidad", pues se entiende que el cierre/extinción de las escuelas rurales conduce al cierre/extinción de las comunidades rurales. Como instrumentos metodológicos, para la elaboración del trabajo se utilizó el estudio bibliográfico y entrevistas.

Palabras clave: cierre de escuelas, política de nucleación, educación rural.

\section{INTRODUÇÃO}

Neste trabalho objetivamos compreender as causas do fechamento de escolas do campo no Municípios de Passos Maia e as consequências do fechamento da Escola Conquista de Sepé para a comunidade. Reiteramos, neste estudo, que a política de municipalização do ensino fundamental e de nucleação de escolas foi um dos principais motivadores do fechamento de escolas no campo. Para dar conta de responder ao nosso objetivo, construímos, na perspectiva de Severino (2013), uma pesquisa de abordagem qualitativa. De maneira que, utilizamos ações de explicar, descrever e compreender, valendo-se também, de representações numéricas para um maior esclarecimento do problema. Além disso, buscamos compreender o assunto e estabelecer diálogos com as bibliografias que abordam sobre o tema fechamento de escolas do campo.

Para compor nossa análise da realidade, realizamos cinco entrevistas com sujeitos escolares que vivenciaram o fechamento da Escola Básica Municipal Conquista de Sepé. As entrevistas semiestruturadas tiveram a intenção de compreender o significado e impactos do 
fechamento da escola na vida do Assentamento Conquista de Sepé. As entrevistas foram submetidas a Analise Textual Discursiva (ATD), metodologia analítica desenvolvida em três etapas: a unitarização em que o texto é fragmentado em unidades de significado; a categorização em que os fragmentos com ideias semelhantes são agrupados e, por fim a comunicação em que são construídos metatextos interpretativos e descritivos a partir dos dados analisados (MORAES; GALIZAZZI, 2007). Para resguardar o anonimato dos entrevistados, optamos pela expressão: Entrevistada A, Entrevistada B, Entrevistada C, Entrevistada D e Entrevistada E.

Os tópicos que seguem apresentam o resultado de nossos estudos. Primeiramente apresentamos os aspectos que envolvem a política de nucleação das escolas. Em seguida o processo de nucleação das escolas do município de Passos Maia, lócus de nossa pesquisa. No terceiro tópico apresentamos o processo de nucleação/fechamento da escola Conquista de Sepé e o impactos no Assentamento. Nas considerações finais, apresentamos que, nesse estudo, obtivemos como resultado que: a política de nucleação implementada em diversos municípios, inclusive em Passos Maia, é a principal causa de fechamento de escolas; o fechamento da escola do campo causa impactos negativo nas comunidades rurais ao dificultar o acesso a escola e ao conhecimento, ao distância à escola das famílias, ao desconsiderar a realidade e a identidade dos alunos; no Município de Passos Maia foram fechadas 20 escolas do campo nas últimas 3 décadas e que ainda há escolas em risco de serem extintas.

\section{POLÍTICA DE MUNICIPALIZAÇÃo dO ENSINO FUNDAMENTAL E DE NUCLEAÇÃO DE ESCOLA E O FECHAMENTO DA ESCOLA DO CAMPO}

O fechamento de escolas no campo segue sendo um debate desafiador para a política de educação brasileira. Segundo Tafarel e Munarim (2014), nos últimos 15 anos (equivalente ao período de 1999 a 2014) mais de 37 mil escolas foram fechadas. Somente no "ano de 2014 mais de 4 mil unidades de escolas do campo fecharam as portas, e as regiões mais afetadas são o Norte e o Nordeste. Se dividirmos esses números ao longo do ano, temos oito escolas rurais fechadas por dia em todo país (MST, 2017)". Com isso, Tafarel e Munarim (2015, p. 45) afirmam que "o fechamento de escolas do campo vem sendo denunciado como um crime contra a nação brasileira." 
Em Santa Catarina, desde o início da política de municipalização do Ensino Fundamental e de nucleação de escolas, muitas escolas foram fechadas. De acordo com Oliveira (2018, p.77), esse processo gerou fechamento compulsório de inúmeras escolas, "sendo que de 1995 a 2011 o número de escolas rurais em atividade no estado diminuiu de 6.857 para 1.541". Isto é, cerca de 5.316 escolas foram fechadas no Estado. Dessas, segundo a autora no meio rural "significou o fechamento de 3,5 mil unidades escolares nessas comunidades (OLIVEIRA, 2018, p.79)".

No caso específico de Santa Catarina a política de nucleação se realizou especialmente na década de 1990, conjuntamente com a municipalização do ensino fundamental. Como destaca Oliveira (2018),

\begin{abstract}
Os argumentos lançados para justificar políticas de municipalização podem, portanto, informar diferentes propósitos, declarados ou reais. Por exemplo, no documento intitulado Diagnóstico sobre a Educação em Santa Catarina, publicado na década de 1990 (SANTA CATARINA, 1994), a via da municipalização é referida como meio de enfrentamento à tendência ao gigantismo da administração estadual, com vistas a dar resposta à lentidão decisória decorrente desta condição. Ao lado desta justificativa, outra destaca que "a municipalização corresponde ao atendimento de ideologias que sustentam atributos de maior eficiência pedagógica (no caso da educação) pelo envolvimento direto e intenso das motivações das comunidades" (p. 162), uma perspectiva de municipalização que, claramente, visa marcar um sentido de pertinência social (OLIVEIRA, 2018, p. 42).
\end{abstract}

O processo de municipalização, já estava em curso no Brasil desde a década de 1970.

Mas foi com o incentivo a descentralização da oferta de educação básica que essa medida ganha mais força na década de 1990. Em Santa Catarina a municipalização das escolas primárias alavancou o processo de nucleação das mesmas, conforme ressalta Oliveira (2018),

\begin{abstract}
Conforme mencionado, no caso brasileiro a nucleação das escolas do meio rural, ocorrida na década de 1990, constituiu-se em alternativa visando ao aumento da eficiência da máquina estatal e à melhoria da qualidade do ensino fundamental, o que inclui a vazão de um discurso de modernização do atendimento escolar. Situada no contexto nacional e no leque de pressupostos neoliberais que ganharam força no país, a nucleação de escolas do meio rural tornou-se uma ferramenta da municipalização, forjada enquanto recurso de um modelo de descentralização a serviço da reforma do Estado (OLIVEIRA, 2018, p. 46).
\end{abstract}

Ou seja, o processo de nucleação foi realizado com a argumentação de que precisava melhorar a qualidade da educação sem aumentar investimentos financeiros. Afirmando uma formação alinhada com os pressupostos neoliberais.

A política de nucleação foi direcionada especialmente para as escolas localizadas em áreas rurais. As escolas nucleadas se caracterizam por agrupar várias unidades escolares em 
uma única escola. No caso das escolas no meio rural eram multisseriadas, conhecidas como escolas isoladas. A nucleação para os órgãos públicos foi vista como uma forma de efetivar uma educação eficiente.

Estudos de Bauman (2013) indicam que o fechamento das escolas localizadas nas comunidades rurais provoca o "fechamento" da comunidade. Isso porque, as escolas nessas localidades funcionam como coração que traz vida a comunidade. E, quando há o fechamento das escolas, as comunidades se enfraquecem. Essa situação pode ser observada ao percorrer os Assentamentos do município de Passos Maia onde nos deparamos com construções que eram escolas anteriormente e que hoje estão abandonadas ou servindo de moradia e/ou igreja.

Tal processo de fechamento de escola, e posteriormente o enfraquecimento das comunidades rurais, aliado a falta de política pública para os sujeitos do campo, vem causando o "esvaziamento" do campo. A saída do campo é reforçada, desde que as crianças, obrigadas a frequentar escola longe de suas casas, recebe um ensino que não valoriza a identidade delas, desconsiderando suas vivencias. Isso dificulta a formação de sujeitos integrado a sua realidade, bem como afasta a família de sua realidade e desconstruí o vínculo com a comunidade e a escola.

Rodrigues (2017) alerta que:

Desvincular as crianças e os jovens da comunidade e da escola pode provocar o desenraizamento da cultura local e de pertença ao grupo. A escola não pode negar a cultura local e a pertença a um grupo social com suas particularidades. (RODRIGUES, 2017, p.4)

A política de nucleação atinge principalmente os municípios do interior do país. Esse processo tem preocupado muito as entidades e movimentos sociais ligados ao campo. Isto porque o fechamento das escolas do campo traz inúmeros problemas especialmente, como já destacados em estudos Bauman (2013), o distanciamento das escolas da vida dos estudantes. E, com isso, é uma forma de incentivo ao êxodo rural.

Foi preocupado com essa realidade que os Movimentos Sociais do campo, especialmente o Movimento dos Trabalhadores Rurais Sem Terra (MST), tem pautado a necessidade de leis que assegurem o direito de viver e estudar no campo. A partir de 2014, por conta de mobilizações sociais, é incluído da LDB Artigo 28, um parágrafo único, que busca frear o processo de fechamento de escolas:

Parágrafo único. O fechamento de escolas do campo, indígenas e quilombolas será precedido de manifestação do órgão normativo do respectivo sistema de 
ensino, que considerará a justificativa apresentada pela Secretaria de Educação, a análise do diagnóstico do impacto da ação e a manifestação da comunidade escolar. (BRASIL, 1996)

A importância da inclusão desse debate na LDB, está na garantia do direito das comunidades se manifestarem diante da possibilidade do fechamento de escola. Algo que até então, não estava previsto. Além disso, a partir da luta por uma Educação do Campo, estão inclusas em diretrizes operacionais da educação básica do campo, no CNE/CEB n ${ }^{\circ}$ 1/2002 art. $2^{\circ}$ parágrafo único que "a identidade da escola do campo é definida pela sua vinculação às questões inerentes à sua realidade, ancorando-se na sua temporalidade e saberes próprios dos estudantes". Tais legislações se tornam imprescindíveis para repensar a política de fechamento de escolas, especialmente, sob a justificativa que sua implantação é a melhor alternativa, como uma educação de maior qualidade e para diminuir custos de funcionários, materiais, manutenção, entre outros. No próximo tópico analisaremos a situação do Município de Passos Maia, e que de maneira geral expressa a realidade das escolas do campo exposta nesta sessão, estadual e nacionalmente.

\section{A POLÍtica de FeCHAMENTO dAS ESCOLAS DE PASSOS MAIA: O CASO da ESCOLA SEPÉ} TIARAJU

O Município de Passos Maia está localizado no meio oeste catarinense, com a população estimada de 4.425 pessoas (IBGE, 2010), dessas 1.099 pessoas moram no perímetro urbano e 3.326 pessoas moram no campo, sendo assim, grande parte em assentamentos da reforma agrária e comunidade de pequenos agricultores (IBGE, 2010). O município tem como base econômica, o setor madeireiro, agricultura e pecuária.

O município lócus de nossa pesquisa é marcado pela luta pela terra que teve início em 1988, quando 12 famílias ocuparam a fazenda, que atualmente é o assentamento Sapateiro I. Neste mesmo período, outras 11 famílias de agricultores Sem Terra de Ponte Serrada, numa articulação entre o município de Ponte Serrada e o Instituto Nacional de Colonização e Reforma Agrária (INCRA), foram assentadas na Fazenda Taborda, hoje Assentamento Taborda (PAVANI, 2015, p.28).

Em 20 de Novembro de 1995, o MST organizou uma grande ocupação de terras na Fazenda Ameixeira. Em torno de 800 famílias oriundas de diversos municípios catarinenses, participaram da ocupação. Outra grande ocupação aconteceu no dia 30 de agosto de 1996, na 
Fazenda Stella, com aproximadamente 1.200 famílias. Essas ações de denúncias despertaram a população sobre a grande concentração de terras no município. Desta forma, ocorreram sucessivas ocupações no município, consolidando 15 assentamentos, com aproximadamente 480 famílias. Essa mudança de configuração fundiária, é compreendida atualmente como responsável por grande parte do desenvolvimento econômico do município (COOPTRASC, 2008).

Como relação à educação no município de Passos Maia, em 1942 foi criada a escola estadual no centro da cidade que existe até hoje denominada Escola Estadual de Educação Básica Professora Corália Gevaerd Olinnger (Tomazelli, 2016), atendendo o ensino fundamental e ensino médio. Quando foi necessário ampliar a oferta de educação para todas as crianças do município, foram criadas escolas municipais, chamadas de Escolas Isoladas. Podemos observar no quadro abaixo a relação de escolas construídas/criadas desde a fundação do município.

\section{Quadro 1 - escolas do município de Passos Maia desde sua fundação}

\begin{tabular}{|l|l|}
\hline Escola & Localidade \\
\hline Escola Adolfo Konder & Madeireira Tupi \\
\hline Escola Presidente Castelo Branco & Madeireira Stella \\
\hline Escola Nossa Senhora de Lourdes & Assentamento Taborda \\
\hline Escola Leoberto Leal & Rio do Poço \\
\hline Escola Professora Dirce Rodrigues & Fazenda São Pedro \\
\hline Escola Aquino Maciel & Santo Antônio \\
\hline Escola Zeferino de Almeida Bueno & Serraria Jardim \\
\hline Escola Bela Planície & Bela Planície \\
\hline Escola Angelo Dal' Apria & Linha Lovison \\
\hline Escola Alberto Zoller & Fazenda Amparo \\
\hline Escola Antônio Giachini & Bela Vista \\
\hline Escola Manoel Osório Ribas & Fazenda Santo Agostinho \\
\hline Escola Guabiroba & Linha Guabiroba \\
\hline Escola Governador Jorge Lacerda & Assentamento Sapateiro \\
\hline Escola Chapecózinho & Dom Carlos \\
\hline Escola Duque de Caxias & Serraria Indumel \\
\hline Escola Maria Francisca Maciel & Indústrias de Madeira Tozzo \\
\hline Escola Nova Conquista & Assentamento Quiguay \\
\hline Escola Governador Jorge Lacerda & Linha Tigre \\
\hline Escola Nossa Senhora Aparecida & Assentamento Zumbi dos Palmares II \\
\hline Escola Nossa Senhora Aparecida & Assentamento 29 de junho \\
\hline Escola Nossa Senhora Aparecida & Assentamento 20 de Novembro \\
\hline Escola Nova Conquista & Assentamento Conquista do Horizonte \\
\hline Escola Conquista de Sepé & Assentamento Conquista de Sepé \\
\hline Eonte: os autores & \\
\hline
\end{tabular}

Fonte: os autores ${ }^{5}$.

4 De acordo com os professores e moradores locais existiam quatro escolas com o nome Escola Nossa Senhora Aparecida, destas foram fechadas três e uma delas foi a receptoras de alunos.

5 O quadro foi produzido a partir de informações obtidas em entrevistas com professores e em Tomazzeli (2016). 
Essas escolas, com o passar do tempo foram sendo incluídas na política de nucleação, principalmente nos anos 1990. Com isso, escolas foram fechadas impulsionadas por uma política de cortes de gastos públicos, justificada pelo baixo número de estudantes.

Atualmente o município possui quatro escolas, sendo duas Escolas de Educação Infantil e Ensino Fundamental, um Centro de Educação Infantil (CEI) e uma escola multisseriada. Destas, três escolas estão situadas no campo, sejam elas: a Escola de Educação Infantil e Ensino Fundamental Duque de Caxias (Chamada popularmente de Escola Indumel, em referência a Serraria de mesmo nome), Escola de Educação Infantil e Ensino Fundamental Nossa Senhora Aparecida; e a Escola de Educação Infantil e Ensino Fundamental Maria Francisca Maciel, essa última com sistema multisseriada. O município conta ainda com a Escola Estadual Professora Corália Gevaerd Olinnger na cidade e uma extensão dela que atende os estudantes de ensino médio no Assentamento Zumbi dos Palmares utilizando estruturas da EEIEF Nossa Senhora Aparecida.

A escola Maria Francisca Maciel (popularmente conhecida como “Escola do Tozzo”), foi, em anos anteriores, uma receptora de educandos atingidos pela política de nucleação. Relato de nossa Entrevistada (E), afirma que duas escolas: Escola Isolada Bela Planície e Escola Isolada Adolfo Konder, instituídas desde o início do município, foram fechadas e incorporadas na época, na Escola do "Tozzo", atualmente esses estudantes são atendidos na Escola Estadual de Educação Básica Professora Corália Gevaerd Olinnger. A Escola "Tozzo", ainda em funcionamento, segundo a entrevistada está correndo risco de ser fechada, e nesse caso será pela segunda vez. Ainda sobre as escolas fechadas a Entrevistada (E) ressalta: "Eu lembro que tinha escola em Guaporézinho, em Fazenda São Luiz, Fazenda São Pedro aqui próximo ao Sapateiro, na Madeireira, na Dirce Rodrigues onde hoje tem um aviário aqui perto da Tupi”.

É importante ressaltar que as escolas, localizadas no meio rural, historicamente eram construídas para atender as demandas os trabalhadores das fazendas e serrarias que existiam no município. À medida que, as serrarias foram se extinguindo, as escolas também foram fechando, obrigando aos trabalhadores a mudarem para outros locais. As escolas fechadas eram multisseriadas, atendendo educandos da Educação Infantil ao quinto ano em uma com duas ou mais séries na mesma sala. As escolas eram situadas na comunidade, bem próxima a residência dos educandos, ou seja, nas fazendas, serrarias, comunidades de pequenos agricultores e Assentamentos da Reforma Agrária. 
A Escola de Educação Infantil e Ensino Fundamental Duque de Caxias atendia os educandos filhos dos funcionários da serraria Indumel. Com a política de nucleação aos poucos foi sendo ampliada, e se tornou receptora de estudantes das escolas fechada na região ${ }^{6}$. Segundo a Entrevistada (E) as escolas incorporada na EIEF Duque de Caxias foram: "Madeireira Stella, que é da escola Castelo Branco, os alunos da Serraria Jardim, chamada na época de Zeferino Almeida Bueno, e na época houve aqui a ocupação no Maria Rosa, foi improvisado uma escola em lonas, e costaneira, depois começaram a ser encaminhados pra Indumel".

A nucleação permitiu que a Escola Duque de Caxias ainda permaneça aberta, atualmente atendendo em sua maioria estudantes de Assentamentos da Reforma Agrária. Nesta escola, estão incorporadas as escola fechadas: 1) Escola Presidente Castelo Branco que ficava localizada na Madeireira Stella, a qual foi fechada no final de 1998; 2) Escola Nossa Senhora de Lourdes, situada no Assentamento Taborda; 3) Escola Zeferino de Almeida Bueno, localizada na Serraria Jardim, onde ambas foram fechadas no ano de 1998, e incorporados no ano de 1999; 4) Escola no Acampamento Maria Rosa e 13 de Junho, desde 1999; 5) Escola Nova Conquista, no Assentamento Quiguay, que foi fechada no ano de 2013, 6) Escola Conquista de Sepé, também fechada no ano de 2013, e incorporadas no ano de 2014.

Outra escola no município receptora de estudantes das escolas fechadas foi a EEIF Nossa Senhora Aparecida, localizada no Assentamento Zumbi Dos Palmares I, que foi inaugurada em fevereiro de 2004. No primeiro ano funcionou em um único turno (vespertino); já no ano seguinte 2005, a escola atuou dois períodos (SOUZA, 2017). Essa escola já existia, somente recebeu uma construção nova na intenção de efetivar a nucleação. $\mathrm{Na}$ sua implantação foram fechada seis escola: 1) Escola Alberto Zoller localizada na Fazenda Amparo; 2) Escola Manoel Osório Ribas, da Fazenda Santo Agostinho; 3) a escola Escola Aquino Maciel, da Comunidade Santo Antônio; 4) Escola Nossa Senhora Aparecida do Assentamento Zumbi II; 5) Escola Nossa Senhora Aparecida do Assentamento 29 de Junho e; 6) Escola Nossa Senhora Aparecida no Assentamento 20 de novembro. Em 2016, a

6 Vale ressaltar que esta escola fica localizada em uma área privada, onde antigamente era uma serraria, e um tempo depois o proprietário da terra doou o terreno para a prefeitura, e hoje recebe educandos de todos os assentamentos arredores, atingidos com a política de nucleação. 
Escola Nova Conquista ${ }^{7}$ do Assentamento Conquista do Horizonte também foi fechada e incorporada EEIF Nossa Senhora Aparecida.

A entrevistada (E), afirma ainda que as escolas: "Sapateiro e Tigre vieram pra cidade, foi diminuindo o número de alunos e, até foi tentado colocar a Educação Infantil no Sapateiro, ficou um pouco de tempo e parou também, e daí os alunos do Tigre vieram pro Sapateiro e depois vieram pra cidade". Isto é, a escola Governador Jorge Lacerda, que se situava na Linha Tigre, uma comunidade de agricultores familiares do município, quando fechou no ano 2010, os educandos foram incorporados na Escola Governador Jorge Lacerda ${ }^{8}$ localizada no Assentamento Sapateiro. Essa escola em 2012, acabou sendo fechada e os educandos incorporados na EEEB Professora Corália Gevaerd Olingger, localizada no centro da cidade de Passos Maia.

A Entrevistada (E) relata que mais quatro escolas foram fechadas: "Rio do Poço fechou da região do Dom Carlos tinha escola da Ângelo Dal'Apria que é da Linha Lovison, tinha escola na Bela Vista, e tinha escola no Dom Carlos". Ou seja, a Escola Leoberto Leal, localizada na comunidade do Rio do Poço, e, a Escola Ângelo Dal'Apria, na Linha Lovison, e, ainda, Escola Antônio Giachini, localizada na comunidade de Bela Vista, foram fechadas nos anos de 1998 e 1999; alguns educandos foram incorporados na escola no centro do município, e outros passaram a frequentar uma escola mais próxima de suas casas, localizada no município de Vargeão. Recentemente, no ano de 2017, a Escola Chapecózinho foi fechada ${ }^{9}$ e seus estudantes encaminhados para escolas no meio urbano. Tais localidades, são comunidades rurais de agricultores familiares.

Observa-se que o no município de Passos Maia, já foram fechadas 20 escolas do campo. Esse fato tem como principal causa, como já salientamos, a política de nucleação que o município aderiu a partir do final da década de 1990. É importante perceber, que há duas escolas receptoras de estudantes no campo; e uma escola na cidade receptora de alunos de escolas fechadas em comunidades camponesas.

Para ilustrar e identificar os impactos causados com o fechamento de escolas do campo traremos a seguir um relato de uma das escolas fechadas, a Escola Conquista de Sepé.

\footnotetext{
${ }^{7}$ Em 2021 foi reaberta.

${ }^{8}$ Ambas as escolas têm o mesmo nome por ser extensão da outra.

9 Essa foi a última escola fechada até o momento de nossas pesquisas.
} 


\section{ASSENTAMENTO CONQUISTA DO SEPÉ: IMPACTOS COM O FECHAMENTO DA ESCOLA}

O Assentamento Conquista de Sepé é resultado da luta do Movimento dos Trabalhadores Rurais Sem Terra (MST). A ocupação da área chamada Fazenda Norte aconteceu no dia 23 de Janeiro de 2005, nesta terra existia plantio de pinus e erva mate, e foi adquirida através de Escritura Pública de Compra e Venda no dia 14 de Agosto de 2006, e sua criação ocorreu no dia 29 de setembro de 2006 a partir da PORTARIA/INCRA/SR-10/n 001/2006 (INCRA, 2006 apud PAVANI, 2015).

$\mathrm{O}$ assentamento fica a uma distância de $8 \mathrm{~km}$ da sede do município, sua área é de 526.831 hectares, sendo 79.81 ha de área de preservação permanente e 105.36 ha de reserva legal (COOPTRASC, 2008 apud PAVANI, 2015). As vinte e cinco famílias que compõem o assentamento são oriundas dos municípios de Passos Maia, Abelardo Luz, Ipuaçú pertencente do Oeste do Estado de Santa Catarina e de Palmas da região sudoeste do Paraná (PAVANI, 2015).

No decorrer do processo de construção do assentamento, houve vários avanços, quanto a construção de casas, energia elétrica, água encanada, transporte escolar e estradas que permitem acesso a todas as moradias do assentamento. No Assentamento Conquista de Sepé, há um centro comunitário, usado para reuniões, promoções e lazer da comunidade, e a estrutura da antiga escola Conquista de Sepé, atualmente usada como igreja pela comunidade.

A lembrança dos moradores referente à escola é registrada na memória: "quando era lá a escola, no assentamento, a comunidade era bem unida, tinha horta também, onde nós plantava e depois cada aluno levava pra casa com maior orgulho de colher algo que nós plantava e ajudava cuidar (ENTREVISTADA B)". Além da produção dos alimentos em suas propriedades, a comunidade produzia coletivamente (educandos, educadores e a comunidade) na horta da escola Conquista de Sepé, onde parte era usada para o lanche dos educandos e outra era dividida entre os educandos para levarem para suas casas.

A escola Conquista de Sepé foi fundada em 2005, logo após a ocupação da área. As crianças até o quinto ano frequentavam esta escola, as outras do Ensino fundamental II e Ensino Médio frequentavam a escola da sede do município, e para EIEF Duque de Caxias, na Serraria Indumel. No entanto, acabou sendo fechada no final do ano de 2012, em uma decisão do poder público Municipal. Conforme relato das entrevistadas, 
No dia do fechamento da escola houve uma reunião e foi colocado essa de que fechar escola do campo é um crime, e nem por isso as pessoas se sensibilizaram, e nem pela aprendizagem dos alunos, nem pelos membros da comunidade, ninguém se sensibilizou, foram poucos os sensibilizados e acabou por fechar (ENTREVISTADA D).

Foi uma decisão da secretaria municipal de educação, eles fizeram uma reunião aqui na comunidade, chamaram todos os pais, os alunos e falaram que iam fechar por que tinha pouco aluno, falta de estrutura física, por que era uma casa antiga, de madeira e que não tinha condições de funcionar uma escola lá, que por motivos financeiros também (ENTREVISTADA C).

Os fragmentos de textos acima indicam que os motivos que levaram ao fechamento das escolas, argumentados pelo governo municipal, foram especialmente a estrutura física, o baixo número de alunos e as questões financeiras. Tais aspectos, não convenceram a comunidade, que compreendem esses como argumentos supérfluos. Isto porque, para a comunidade a falta de estrutura não pode ser motivo de fechamento de escola.

O processo de nucleação é desenvolvido muitas vezes sem qualquer tipo de diálogo com as comunidades, apenas com algumas conversas superficiais. Gerando conflitos nas famílias destas comunidades, acaba se desestruturando quanto à colaboração a socialização entre as famílias,

\footnotetext{
Quando houve o fechamento da escola, eu acho que a comunidade perdeu, olha, um setenta por cento da vida que tinha, por que a gente tinha uma horta bonita, tinha uma escola bonita, tinha o envolvimento de todos, a gente procurava envolver todo mundo, e ai quando foi fechada a escola isso se perdeu, eu vou diariamente, eu passo diariamente pela comunidade, a gente percebe que está tudo desleixado, está tudo morto, tudo sem vida, abandonado. Eu creio que por questões políticas, muitos valores, muitas coisas bonitas foram se perdendo, educação do campo e foi uma coisa muito triste, tanto pra mim como professora, como para os pais, como para a comunidade em geral. Acho que todo mundo ficou triste, e foi uma perda muito grande (ENTREVISTADA D).
}

Muitos valores, culturas desse povo acabam sendo esquecidas, obrigando-os a mudar repentinamente suas rotinas, tendo que se adaptar as mudanças causadas pela nucleação. Para a comunidade não foi levado em conta à voz da comunidade, o apelo dos educandos, dos professores, quando da decisão de fechar a escola.

O principal motivo foi a redução de alunos, que a cada ano vinha se acentuando mais é, ao ponto de ter escolas com quatro alunos, cinco alunos. A perspectiva pro ano seguinte era de três alunos, não tinha condições de manter toda uma estrutura de uma escola com três, quatro alunos, e a receita dos municípios a cada ano tá sendo menor. $\mathrm{O}$ barulho é maior, mas o resultado financeiro pros municípios a cada ano se compromete mais, basta ver este ano 2018 os municípios estão tendo uma dificuldade enorme, enorme, pra manter a educação é uma máquina muito pesada, 
muito necessária, é uma secretaria assim de linha de frente nos municípios. Mas não houve assim, um critério, não foi realizado, essa vai ser fechada pelo prazer de fechar não! todas tiveram a origem foi a mesma diminuição a cada ano menos alunos na escola, foi este o principal motivo (ENTREVISTADA E).

Cabe destacar, que ao fechar a escola os estudantes passaram a utilizar o transporte escolar, tendo em vista, que com as escolas próximas as suas casas, os estudantes se deslocavam a pé, trajeto que com a distância exigiu ônibus, que percorre longas distâncias e o trajeto é feito geralmente quatro vezes por dia. Fica evidente na fala das entrevistadas o aspecto positivo da escola na comunidade: "ficava mais perto da casa e os pais eram bem unidos (ENTREVISTADA B)"; além disso, "morarem ali perto de suas casas, voltarem pra casa antes, chega na escola antes (ENTREVISTADA D)". O atraso para chegar na escola ou no retorno para casa se agrava quando o transporte escolar gera problemas, por conta da estrada esburacada ou do ônibus quebrar, principalmente quando é feito do campo para a cidade.

Referente aos custos, ainda, podemos evidenciar nos estudos de Taffarel e Munarim (2015), numa escola próximo da casa dos estudantes, o gasto pelo governo por aluno, se reduz:

\begin{abstract}
O custo médio por aluno/ano na Educação do Campo, mantido um grau de qualidade equivalente ao urbano, será superior a este, o que decorre de diversos fatores como, por exemplo, da população rarefeita, determinando longas distâncias e uma relação numérica de alunos por professor e por escola menos concentrada. Mais alto ainda será o custo para compensar o déficit histórico acumulado no que concerne à educação dos povos do campo, tanto em termos de quantidade quanto de qualidade. Entendemos, todavia, que a superioridade desses custos se revela tão somente na estrita contabilidade econômico-financeira imediata, tais são os altos custos humanos e mesmo econômicos do êxodo rural involuntário e das concentrações urbanas desordenadas (TAFFAREL; MUNARIM, 2015, p. 49).
\end{abstract}

Já com a distância tais custos aumentam consideravelmente. Outro aspecto evidenciado nas entrevistas, foi quanto o que a distância pode provocar.

Ficou muito difícil pela distância, pelo horário que as crianças saem de casa é muito cedo. Assim os alunos tiveram que mudar de escola, se distanciar de suas casas, e isso ocasionou um distanciamento com as famílias e a comunidade pois a escola era um meio de união do assentamento (ENTREVISTADA C).

Os educandos desta comunidade se deslocam até a escola por meio de transporte escolar, percorrendo aproximadamente $25 \mathrm{~km}$ até a escola, permanecendo uma hora e meia, dentro do ônibus. Essa realidade se opõe às orientações do Estatuto da Criança e do Adolescente (ECA) em seu artigo 53 e incisos I e V, que trata das condições para os 
estudantes: "I- Igualdade de condições para o acesso e permanência na escola; V- acesso à escola pública e gratuita próxima de sua residência. (BRASIL, 1990)" Percebe-se que o direito de os educandos ter uma educação de qualidade, condições de ensino e acesso iguais, e principalmente que a escola seja o mais próximo de suas casas, vem sendo negligenciados pelas más condições de acesso e permanência na escola. Isto é, a cada escola do campo fechada, essa lei não é levada em conta, como exemplo o caso da Escola Conquista de Sepé.

A CNE/CEB em sua resolução $n^{\circ} 2 / 2008$, enfatiza no seu artigo $3^{\circ}$, inciso 1 que:

Os cinco anos iniciais do Ensino Fundamental, excepcionalmente poderão ser oferecidos em escolas nucleadas, com deslocamento intracampo dos alunos, cabendo aos sistemas estaduais e municipais estabelecer o tempo máximo dos alunos em deslocamento a partir de suas realidades. (BRASIL, 2012, p.54)

Embora a legislação educacional estabeleça isso, é notável que, assim como a distância residência/escola, o tempo e o deslocamento desses educandos, na sua maioria era feito do campo para a cidade, prejudicando assim o desenvolvimento educacional dessas crianças. Pois muitos saem muito cedo de casa, passam mais de duas horas dentro do transporte escolar, muitas vezes saem sem alimentação, chegando até a escola sem nenhuma condição física para aprender. Além disso, não leva em consideração a educação e o processo de formação humana desses indivíduos, onde o ambiente na qual estão inseridos é o que promove este aprendizado, e mantém as suas tradições e culturas.

Com a nucleação as escolas ficaram longe das casas dos educandos. Com isso as crianças percorrem longas distâncias para chegar até a escola, permanecendo, muitas vezes, mais tempo dentro do transporte escolar do que na escola. A CNE/CEB n ${ }^{0}$ 2/2008, em seu artigo $4^{\mathrm{o}}$, ressalta que quando não puder ser ofertado a educação nos anos iniciais nas próprias comunidades dos educandos, a nucleação bem como a definição do local e as possibilidades de as crianças fazerem o percurso a pé na menor distância, contará com a participação das comunidades interessadas. No mesmo artigo $4^{\circ}$, em seu parágrafo único da $\mathrm{CNE} / \mathrm{CEB}$ $\mathrm{n}^{\circ} 2 / 2008$, está destacado que: “Quando se fizer necessária a adoção do transporte escolar, devem ser considerados o menor tempo possível no percurso residência/escola e a garantia de transporte das crianças do campo para o campo."

No caso da escola em questão o transporte da maioria das crianças é feito do campo para o campo, porém o tempo dentro do transporte escolar é muito longo. Neste relato, a entrevistada evidencia o orgulho de ter essa escola mais próxima de suas famílias “eu gostava 
muito por que era mais perto da casa e isso era um uma coisa boa, a gente tinha mais gosto em estudar" (ENTREVISTADA A).

Observamos nas falas dos entrevistados que, ao fechar a escolas do campo, não foi valorizado e nem levado em conta as particularidades do sujeito do campo, do povo camponês que tantas culturas têm a cultivar e a ensinar. Oliveira, (2015), salienta a atenção e o respeito à especificidade do campo, no sentido de que a diversidade seja cultivada, tendo a educação como meio de incentivar o pensar e o ser. Tais aspectos desconsideraram os significados políticos e sociais na mudança do campo para a cidade desses sujeitos.

Bem como, desconsideram, a legislação que tratamsobre as escolas do campo, que prevê um tratamento diferenciado a essa população, como é o caso das diretrizes operacionais para a educação básica das escolas do campo em seu Art. $2^{\circ}$ em seu parágrafo único ressalta:

\begin{abstract}
Parágrafo único: a identidade da escola do campo é definida pela sua vinculação ás questões inerentes à sua realidade, ancorando-se na temporalidade e saberes próprios dos estudantes, na memória coletiva que sinaliza futuros, na rede de ciências e tecnologias disponíveis na sociedade e nos movimentos sociais em defesa de projetos que associem as soluções exigidas por essas questões à qualidade social da vida coletiva do país (BRASIL, 2012, p. 33).
\end{abstract}

A escola deve se adequar e respeitar as peculiaridades, as culturas regionais e específicas de cada comunidade escolar, de cada indivíduo. As crianças vêm de uma realidade própria, de áreas rurais. Sobre esse aspecto, a mesma legislação discorre:

\footnotetext{
Artigo $5^{\circ}$, traz que as propostas pedagógicas das escolas do campo deve respeitar as diferenças e assegurar o direito a igualdade e cumprindo imediata e plenamente o estabelecido nos artigos 23,26, e 28 da Lei 9.394, de 1996, contemplarão diversidade do campo em todos os seus aspectos: sociais, culturais, políticos, econômicos, de gênero, geração e etnia (BRASIL, 2012, p. 34).
}

Esta realidade menosprezada, carrega consigo marcas de preconceitos culturais, que vai desde o modo de se vestir, do modo de falar, do modo de expressar o seu modo de viver e de interpretar a realidade. Essas vivências ficam marcadas na memória dos sujeitos ao ter que se deslocar de uma escola para outra: "Foi bem estranho, por que eu não conhecia ninguém, e o jeito de estudar era diferente (ENTREVISTADA A)".

Em outro trecho, podemos observar, que a forma e o conteúdo dificultaram a vinculação das crianças a outros ambientes: "O número de alunos ser muito grande, a forma de trabalhar na escola não é a mesma, não é mais a Educação do Campo, essa educação foi esquecida (ENTREVISTADA D)". Ainda, em outras entrevistas destacam-se as dificuldades encontradas pelas crianças nesta mudança de escola, como podemos ver a seguir: 


\begin{abstract}
As crianças tiveram dificuldades? sim com certeza! Saída da propriedade, da comunidade vim pra cidade, toda essa adaptação um novo ambiente, pra criança leva um certo tempo pra ela aceita, que ela não ta mais ligada a escola de sua comunidade, tem um grupo de colegas novos, vai ter que conhecer, numa escola maior tem muitos professores, tem muita gente, mais serventes, uma outra dinâmica, e a criança sofre pra se adapta a isso (ENTREVISTADA E);
\end{abstract}

Aqui as turmas são muito grandes, as professoras trocam cada 45 minutos é bem difícil a gente se adaptar com essas mudanças. Lá na escola do assentamento as professoras davam mais atenção (ENTREVISTADA B)

Tais fragmentos revelam, que as dificuldades enfrentadas, que reflete na aprendizagem dos estudantes, essa mudança acaba retraindo a criança, no seu desenvolvimento intelectual e social. Isto porque, havia uma relação de confiança, de companheirismo entre a comunidade escolar. As dificuldades encontradas nas escolas multisseriadas, eram superadas pelo ensino aprendizagem que acontecia com mais facilidade, conforme afirma a entrevistada,

\begin{abstract}
Não tinha acesso à internet, a gente nem tinha computador na escola, mas os alunos conseguiam aprender a ler antes, todos sabiam a tabuada, assim era, parece mais fácil, eles aprendiam com mais facilidade, o entrosamento entre os alunos com os professores que na época eram dois, era bastante grande, a gente tinha facilidade de chegar nos alunos, facilidade de cobrar, até por que os pais também estavam sempre envolvidos (ENTREVISTADA D).
\end{abstract}

Observamos no trecho acima, que a havia participação dos pais na educação de seus filhos, e isso se refletia dentro da sala de aula, na aprendizagem da criança. Isto é, a escola na comunidade, perto de suas residências, facilita o acompanhamento dos pais, como relata a entrevistada: "daí eu levava eles pra casa, chegava nas casas tomava chimarrão, tudo assim, a interação com a família era muito bom, e assim eu vejo que era um respeito com a gente (ENTREVISTADA D)".

Depois do fechamento da escola, percebemos que uma das reclamações frequentes das escolas é a não participação efetiva dos pais. Por outro lado, os pais sentem a dificuldade para acompanhar seus filhos, da interação com a escola e com o educador. Esses aspectos refletem na aprendizagem dos educandos, como é ilustrado na fala da entrevistada: "Agora o que acontece que eles estão estudando bem distante da sua casa, os pais sentem dificuldade de estar indo na escola acompanhar, e naquela época o acompanhamento dos pais era maior, talvez por isso havia mais aprendizagem (ENTREVISTADA D).

Percebemos nas entrevistas que o vínculo da escola com a comunidade era um dos valores mais importante na Escola Conquista de Sepé, especialmente para o desenvolvimento 
da educação das crianças. Esse aspecto foi destacado no relato da Entrevistada: "a escola precisava da comunidade e a comunidade precisava da escola para se manter em pé, nós os pais sempre estávamos na escola sempre acompanhando nossos filhos na educação e ajudando sempre que precisasse (ENTREVISTADA C)". O fechamento desta Escola interferiu na vida desses educandos e de toda a comunidade.

Tais elementos elencados pelas entrevistas, são analisados por Taffarel e Munarim (2015), como formas de violências,

\begin{abstract}
Considerando que a Educação tem sua especificidade e natureza delimitada ontologicamente nos fundamentos e princípios que possibilitam nos tornarmos seres humanos, fechar escolas representa um violento ataque à própria humanização da população da nação brasileira. Configura-se um crime contra uma nação e sua classe trabalhadora, em especial aos povos do campo, florestas e águas. (TAFFAREL; MUNARIM, 2015, p.45)
\end{abstract}

É importante destacar que há distância entre as legislações existentes no Brasil e as práticas adotadas pelos órgãos públicos em relação à Educação do Campo, nas escolas do campo. Pois a LDB, 1996 estabelece em seu art. 28, da Lei Federal n. 9.394:

\footnotetext{
Art. 28. Na oferta de educação básica para a população rural, os sistemas de ensino promoverão as adaptações necessárias à sua adequação às peculiaridades da vida rural e de cada região, especialmente: I - conteúdos curriculares e metodologias apropriadas às reais necessidades e interesses dos alunos da zona rural;

II - Organização escolar própria, incluindo adequação do calendário escolar às fases do ciclo agrícola e às condições climáticas; III - adequação à natureza do trabalho na zona rural (BRASIL, 1996).
}

Como é destacado nas entrevistas, o ensino nas escolas multisseriada é desenvolvido coletivamente, e a aprendizagem acontece de forma rápida, com interação entre os educandos, onde trocam conhecimentos. Há uma relação de confiança, de amizade, de compromisso e principalmente de coletividade entre educandos e educadores, tornando assim a aprendizagem mais significativa. A valorização dos conhecimentos prévios dos educandos é importante para o processo de ensino-aprendizagem, uma vez que é por meio de tais conhecimentos, da interação, da troca de experiências, das vivencias que acontece a aprendizagem.

Diante do exposto, podemos concluir que os principais impactos que a comunidade Conquista de Sepé sofreu com o fechamento das escolas foram os seguintes: a) Distanciamento da escola com as famílias, isto porque, a retirada da escola da comunidade proporcionou uma perda da pertença das famílias com a escola; b) Um segundo elemento é quanto a pouca valorização da identidade dos estudantes evidenciada na escola nucleada; c) 
Um outro aspecto impactante está relacionado a distância percorrida em transportes escolar dos estudantes até a escola nucleada, ocasionando várias horas em ônibus prejudicando a aprendizagem dos mesmos; d) Por fim, outro impacto, a retirada da escola da comunidade causou o "fechamento" da comunidade, pois a escola do campo movimenta e dá vida à comunidade.

\section{CONSIDERAÇÕES FINAIS}

Neste trabalho analisamos à política de nucleação de escolas, apresentamos dados sobre o fechamento de escolas do campo no município de Passos Maia e expusemos os impactos dessa política na comunidade Conquista de Sepé.

Como resultado deste estudo, destacamos alguns elementos. Um deles é que a política de nucleação implementada foi a principal causa de fechamento de escolas no município de Passos Maia. Notadamente, a política de fechamento de escola do campo, esta alicerçada num projeto de avanço do capital que, no campo, aparece através do modelo do agronegócio. Tal modelo gera a expulsão dos trabalhadores do campo, tornando o fechamento de escola no campo uma das estratégias e consequências.

Outro aspecto resultante dessa pesquisa é o impacto obtido por umas das comunidades em que a escola foi fechada, sendo estes: Distanciamento da escola com as famílias; pouca valorização da identidade dos estudantes; Aumento da distância percorrido pelos estudantes em transporte escolar prejudicando o acesso à escola e a aprendizagem; O "fechamento" da comunidade, pois a Escola do Campo é "vida na Comunidade" e ao fechar a escola "fechase" a comunidade.

Tivemos ainda, como resultado, o registro atualizado das escolas fechadas no município de Passos Maia e sua localização. Salientamos que todas as escolas fechadas no referido município eram do campo.

Por fim ressaltamos que, dado a abrangência, importância e complexidade da temática abordada neste artigo, é necessário ainda de darmos continuidade no aprofundamento deste estudo. Tal desafio poderá ser enfrentado em futuros estudos e/ou trabalhos científicos. Especialmente, no que tange, o vínculo do fechamento de escolas no campo com o projeto de campo que se pretende no Brasil. 


\section{REFERÊNCIAS}

ARROYO, Miguel. A Educação Básica e o Movimento Social do Campo. In: ARROYO, Miguel; CALDART, Roseli; MOLINA, Mônica (org.). Por Uma Educação do Campo: Vozes, 2004

BAUMANN, Siuzete Vandresen. Da vida das escolas rurais isoladas a uma escola isolada da vida rural: aprendizagens do processo de nucleação em santa rosa de lima. Goiânia: ANPED, 2013.

BRASIL. Lei de Diretrizes e Bases para a Educação Nacional - LDB. Brasília: MEC, 1996. Disponível em: https://www.cpt.com.br/ldb/lei-de-diretrizes-e-bases-da-educacaocompleta-interativa-e-atualizada. Acesso em: 30/11/2018

BRASIL. Educação do Campo: Marcos Normativos. Secretaria de Educação continuada, alfabetização, diversidade e inclusão. Brasília: MEC/SECADI, 2012.

ENTREVISTADA A. Aluno da Comunidade Conquista do SEPÉ. Entrevista realizada em 10 de outubro de 2018.

ENTREVISTADA B. Aluno da Comunidade Conquista do SEPÉ. Entrevista realizada em 10 de outubro de 2018.

ENTREVISTADA C. Pai de aluno da Comunidade Conquista do SEPÉ. Entrevista realizada em 10 de outubro de 2018.

ENTREVISTADA D. Professora da Rede Municipal de Educação de Passos Maia. Entrevista realizada em 20 de outubro de 2018.

ENTREVISTADA E. Professora da Rede Municipal de Educação de Passos Maia. Entrevista realizada em 28 de outubro de 2018.

MORAES, R.; GALIAZZI, M.C. Análise Textual Discursiva. Ijuí: Editora Unijuí, 2007.

MST. Mais de 4 mil escolas do campo fecham suas portas em 2014. Disponível em: http://www.mst.org.br/2015/06/24/mais-de-4-mil-escolas-do-campo-fecham-suas-portasem-2014.html. Acesso em: 05/07/2018

OLIVEIRA, Katia Lucena Alves de. Política de Nucleação de Escolas do Meio Rural: Repercussões em Comunidades do Oeste Catarinense. Programa de Pós-graduação em Educação, UNOESC, Joaçaba, 2018.

PAVANI, Greti Aparecida. Os Jovens no Mundo do Trabalho e o Trabalho no Horizonte dos Jovens: Análise [...]. Universidade Federal de Santa Catarina Curso de Especialização em Educação do Campo e Desenvolvimento Sustentável com base na Agroecologia (Residência Agrária). Florianópolis, 2015. 
PEIXER, Zilma Isabel et al. Comunidades Rurais e Escolas: O Fechamento [...]. Disponível em: http://www.sbpcnet.org.br/livro/65ra/resumos/resumos/8545.htm Acesso em 27/06/2018.

PASSOS MAIA. https://www.passosmaia.sc.gov.br/municipio/index/codMapaItem/13743. Acesso em: 23/10/2018

RODRIGUES, Ana Cláudia da Silva et al. Nucleação de Escolas no Campo: conflitos entre formação e desenraizamento. Porto Alegre: Educação e Realidade, 2017.

SEVERINO, A. J. Metodologia do trabalho científico. 23 ed. rev. e atual. São Paulo: Cortez, 2013.

TAFFAREL, C. Z.; MUNARIM, A. Pátria educadora e fechamento de escolas do campo: o crime continua. Revista Pedagógica, Chapecó, v. 17, n. 35, p. 41-51, maio/ago. 2015

TOMAZELLI, Simone Leandra. Passos Maia a muitas mãos. Secretaria Municipal de Educação e Esportes. Passos Maia, 2016. 